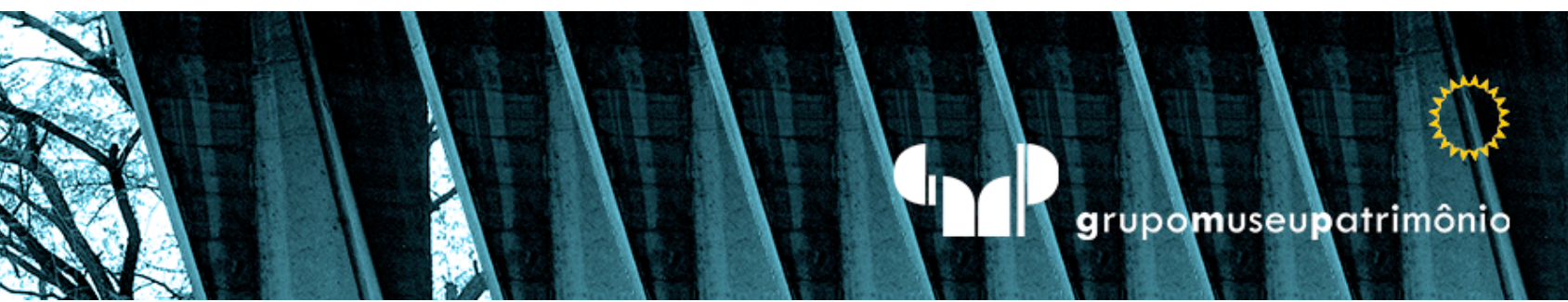

\title{
Traduzindo bits, exposições virtuais na pandemia
}

\author{
Translating Bits, \\ virtual exhibition during the pandemic \\ Traduciendo Bits, \\ exposición virtual durante la pandemia
}

Amanda Saba Ruggiero

Faculdade de Arquitetura e Urbanismo FAU-USP, São Paulo, Brasil. amandaruggiero@usp.br 


\title{
Resumo
}

O que são as exposições digitais nas plataformas tecnológicas em realidade pandêmica: uma possibilidade de contato e introspecção por meio da arte, ou apenas uma forma encontrada pelas instituições e pelo mercado de arte em não suspender contato ou consumo de seu público? Em que medida mostras virtuais propiciam espaços de interlocução e conhecimento, ou simples deleite e prazer contemplativo, em que pesem simulacros espaciais revestidos por chancelas de grandes nomes ou instituições? Tais mensagens, adequadas digitalmente, constituem paradigma das novas relações e interações humanas?

Palavras-Chave: Exposição. Tradução. Digital. Pandemia. Espaço.

\section{Resumen}

¿Qué son las exposiciones digitales en plataformas tecnológicas en una realidad pandémica: una posibilidad de contacto e introspección a través del arte, o simplemente una forma que encuentran las instituciones y el mercado del arte para no suspender el contacto o consumo por parte de su audiencia? ¿En qué medida las exposiciones virtuales brindan espacios de diálogo y conocimiento, o simple deleite y placer contemplativo, a pesar de los simulacros espaciales cubiertos por sellos de grandes nombres o instituciones? ¿Los mensajes en la adaptación al medio digital constituyen un paradigma de nuevas relaciones e interacciones humanas?

Palavras-Clave: Exposición. Traducción. Digital. Pandemia. Espacio.

\begin{abstract}
What are digital exhibitions on technological platforms in a pandemic reality: a possibility of contact and introspection through art, or just a way found by institutions and the art market in not suspending contact or consumption by their audience? To what extent virtual exhibitions provide spaces for dialogue and knowledge, or simple delight and contemplative pleasure, despite spatial simulacra covered by seals of big names or institutions? Do such encounters or translated forms constitute a paradigm of new human relationships and interactions, in adapting the message to the digital medium?
\end{abstract}

Keywords: Exhibition. Translation. Digital. Pandemic. Space. 


\section{DA INTROSPECÇÃO AO IMPREVISÍVEL}

Durante as horas de perdição tive a coragem de não compor nem organizar. E, sobretudo a de não prever. Até então eu não tivera a coragem de me deixar guiar pelo que não conheço e em direção ao que não conheço: minhas previsões condicionavam de antemão o que eu veria. Não eram as antevisões da visão: já tinham o tamanho de meus cuidados. Minhas previsões me fechavam o mundo

(LISPECTOR, 2014, p.9)

Darte-se de dois aspectos relacionados ao tema: Outro ato em direção ao caminho inverso para reflexão no texto a seguir: primeiro a introspecção e o essencial, na despersonalização da protagonista de Clarice Lispector em " A paixão segundo G.H.", ou o "simplesmente ser"; e segundo, a surpresa como recurso formal de sua linguagem, em que o acidental, o imprevisível e o não mimético são gentilmente concedidos ao leitor. Em momento de tamanha fragilidade, caos social e sanitário, crises coletivas e pessoais se interpõem em telas nos debates, shows e mostras digitais. De que maneira a introspeç̧ão e o imprevisível da arte participaram das nossas vidas? 
De Clarice Lispector nos comove seu obstinado desejo em busca da essência humana, o que resta do ser humano quando a linguagem se esgota. Escritora de invejável empenho e habilidade na tessitura de palavras ora árduas, cadenciadas e fluidas, convictas e ritmadas, numa escrita feita por recomeços, saltos, tensões, memórias e suspensões de tempos. Se a personagem G.H de Clarice Lispector no inesperado e imprevisível experimenta o essencial e o "simplesmente ser", poderíamos ainda ao navegar pelo universo digital encontrar o inesperado, o essencial ou um caminho para a introspecção? O texto da autora sugere um caminho inverso e aqui se procura debater se as soluções museográficas e expográficas implementadas online na pandemia assinalam uma reversão radical daquela fruição em presença? O simples ser, ao retornar integralmente a visitação em presença, corresponderia a uma fórmula mista, ou se manteriam aquelas aqui analisadas?

Enfrentam-se desafios formais ao trabalhar sobre o espaço online, suspendendo dimensionamentos espaciais e deslocamentos urbanos. Neste ensaio crítico parte-se também dos processos e problemas da tradução enunciados por Walter Benjamin, para refletir sobre seleção de mostras virtuais, pensar os modos de reproduzir, induzir ou apresentar as relações entre espaço e obras, adequação e fidelidade ao espaço museal. Visitar exposições é a atividade cada vez mais comum na contemporaneidade, instituições de acesso público ou privado prometem temáticas atraentes, biografias canônicas e a corrida se amplia, move-se pela ânsia em consumir subjetividades, expandem-se pelos ambientes à distância em redes digitais, seja por meio de passeios online ou imersivos, gravados em espaços físicos ou inteiramente produzidos de modo digital, pergunta-se: há ainda alguma perspectiva em ampliar "horizonte existencial"?

\section{DA TRADUÇÃO}

Uma exposição é sempre uma tradução, um sentido construído em relação ao espaço e às relações que se projeta e redesenha. A tradução é uma forma, de acordo com o filósofo alemão Walter Benjamin, para buscá-la é necessário regressar ao original, pois nele reside a lei da tradução, contida na sua traduzibilidade (Übersetzbarkeit). A possibilidade de tradução de uma obra tem um duplo sentido: 
importa saber se a obra encontrará um tradutor à sua altura; ou se de acordo com a sua essência, ela permite sua tradução e assim - a condizer com a importância atribuída àquela forma. (BENJAMIN, 1923, p.26). Seria possível "traduzir" uma mostra física para ambiente virtual?

Uma exposição exige obras dispostas em um espaço: quando telas, a superfície vertical, uma parede ou suporte para sua fixação, esculturas apoiam-se em pedestais, bases, mesas ou peças de grandes dimensões podem ser suspensas ou apoiam-se diretamente no chão. Instalações e performances usam espaços dinâmicos, enquanto vídeos e projeções exigem ambientes escuros e superfícies planas e lisas. Assim, os espaços expositivos tradicionais se organizam em percursos direcionados, livres, organizados ou distribuídos pelo conjunto de elementos determinados pela materialidade e aspectos físicos das obras e do ambiente.

Durante a pandemia em 2020, o ICOM Brasil realizou pesquisa com o público e trabalhadores dos museus (ICOM, 2021), disponibilizando dados em que estes são considerados pelo público como um lugar de convívio. Acrescente-se que dos participantes da pesquisa, um quarto $(24,7 \%)$ desejam maior acessibilidade digital aos museus e uma ampliação da sua programação online. Esta mesma fração daqueles que responderam afirmaram ter tido seu primeiro contato com o museu por meio de alguma atividade digital durante a pandemia. Do mesmo modo, ainda é preciso considerar a saturação do acesso digital, quando pouco mais da metade $(51,2 \%)$ dos participantes da pesquisa não se envolveu em nenhuma programação digital promovida por qualquer museu. Isso pode decorrer da dificuldade em acessar a rede de internet e até a posse de equipamentos adequados para envolvimento em práticas promovidas.

Outros dados interessantes desta pesquisa sobre as ações online, indicam que as mais acessadas são as aulas online, cursos, oficinas ou webinários com $71,4 \%$; lives e/ou transmissões ao vivo de eventos culturais e artísticos, entre shows, peças, apresentações, foram 59,7\%; Metade do público assinalou os debates, reuniões ou discussões online como eventos acessadas; enquanto as exposições online e as visitas virtuais a museus e galerias foi apontado por 33,3\% dos participantes. Assim, percebe-se que as programações digitais são ferramentas de difusão de 
conhecimento sobre os acervos, coleções e temáticas dos museus, embora se afirme a importância do espaço de convívio dos museus. Quando a programação digital está bem planejada e conectada com a missão institucional, amplia-se a acessibilidade e o alcance dos museus, atingindo públicos de outros estados e cidades - alguns dos quais nunca visitaram o museu presencialmente, levando em consideração a desigualdade no acesso a rede de internet e aos equipamentos adequados por grande parte da população brasileira.

Uma exposição quando montada e organizada e seu ambiente configurado, o espaço expositivo pode ser registrado de diversas maneiras, por meio de vídeos, fotografias, desenhos, e recentemente uso comum das maquetes ou modelos eletrônicos. Porém o registro é uma forma de traduzir o espaço físico e material. Assim, a modelagem virtual de uma mostra equivale a uma visita? Se uma exposição é como uma orquestra posicionada, sua sonoridade é acionada pelo trânsito e movimento das pessoas. Escutar a gravação ou assistir a um concerto ao vivo via telas não é o mesmo que estar presente, sentir as vibrações sonoras dos instrumentos com a presença física na sala de concerto. Assim como um espetáculo de dança, uma peça de teatro, ou até mesmo estar em uma sala de cinema, poderíamos aferir o mesmo sentido ao estar fisicamente e visitar uma exposição?

A traduzibilidade de uma obra é a possibilidade de determinado aspecto de sua tradução tocar o original, para Walter Benjamin (2008, p.27), uma tradução, por muito boa que seja, nunca consegue afetar ou até mesmo ter um resultado positivo quanto ao original. Dos problemas da traduzibilidade, ele ressalta primeiro a necessidade em compreender a natureza da obra e interrogar se ela permite ou não uma tradução. A traduzibilidade seria própria de certas obras e assim determinados significados referentes à essência do original passíveis de serem expressos por essa traduzibilidade. Neste sentido perguntamos: uma exposição virtual seria uma versão traduzida para um modo digital? Qual seria seu formato original? O que dizer sobre o catálogo de uma mostra independente de seu tamanho, formato ou conteúdo, é um complemento, um registro, outro produto que tem autonomia e muitas vezes somase aos produtos e documentos oriundos de uma exposição e sua extensa pesquisa. 0 catálogo muitas vezes agrega conjunto de textos e referências que não estavam na 
mostra, ou somente resume o conjunto exposto, mas sempre se configura como um outro produto, registro do evento. Seria o mesmo para um tour virtual?

O website do Museu de Arte Moderna de São Paulo (MAM-SP) apresenta uma página que reúne um conjunto de visitas virtuais de mostras realizadas pelo museu desde 2017, trabalho realizado pela empresa 3D Explora, cuja página hospeda as maquetes virtuais das mostras do museu. A 350 Panorama da Arte Brasileira: Brasil por multiplicação, ficou aberta entre 27 de setembro a 17 de dezembro de 2017, exibe seu conteúdo completo no tour virtual, é possível acessar a planta baixa, a posição e a identificação das obras, títulos e autorias. Estas informações são exibidas quando se posiciona o cursor no quadro, e uma outra tela com escritos se amplia para leitura. O tour pode ser feito no ritmo do visitante, ao direcionar e clicar no cursor nos pontos de vista estruturados pela maquete virtual, ou um vídeo passeio, em que o visitante assiste de modo passivo os espaços virtuais do museu. O passeio enquanto fonte documental, registro do evento e sua organização, memória das obras e das suas relações espaciais, tem no simulacro uma referência completa e interessante para pesquisadores, estudos sobre exposições e curadorias, além do registro do museu de sua programação em bases digitais e acervo da programação.

Se estabelecermos a visita virtual como instrumento exclusivo de apreciação, certamente muito se perde com a ausência física e o contato visual em ambiente real, a qualidade e o foco das imagens de cada obra não tem grande resolução, texturas e cores são secundárias pelo olhar digitalizado virtual. Perde-se nas relações visuais e nas possíveis surpresas, o acidental e o inesperado passam inevitavelmente a serem suprimidos. Ainda que não se considere o percurso de acesso ao espaço do museu, no caso do MAM, caminha-se dentro do Parque /birapuera, cujo conjunto arquitetônico e paisagísticos, jardins, marquises e pavilhões são explorados com a indecifrável surpresa de cada passeio, desde a explosão de cores, verdes, texturas, barulhos, encontros e vidas que avivam a dinâmica do parque, incluindo o generoso Jardim de esculturas em frente ao MAM, cujas esculturas desenham os $6 \mathrm{mil} \mathrm{m2} \mathrm{de}$ área aberta e verde. Talvez, no interior do museu, o espaço mais comprometedor dos registros virtuais seja o corredor, parede que recebe temporariamente obras de artistas, configura um espaço significativo, espécie de ritual ritmado, muito particular 
daquele espaço museal. O registro é válido como documento, mas suprime as nuances do percurso que sempre é algo a se revelar para o transeunte que adentra o espaço expositivo do MAM.

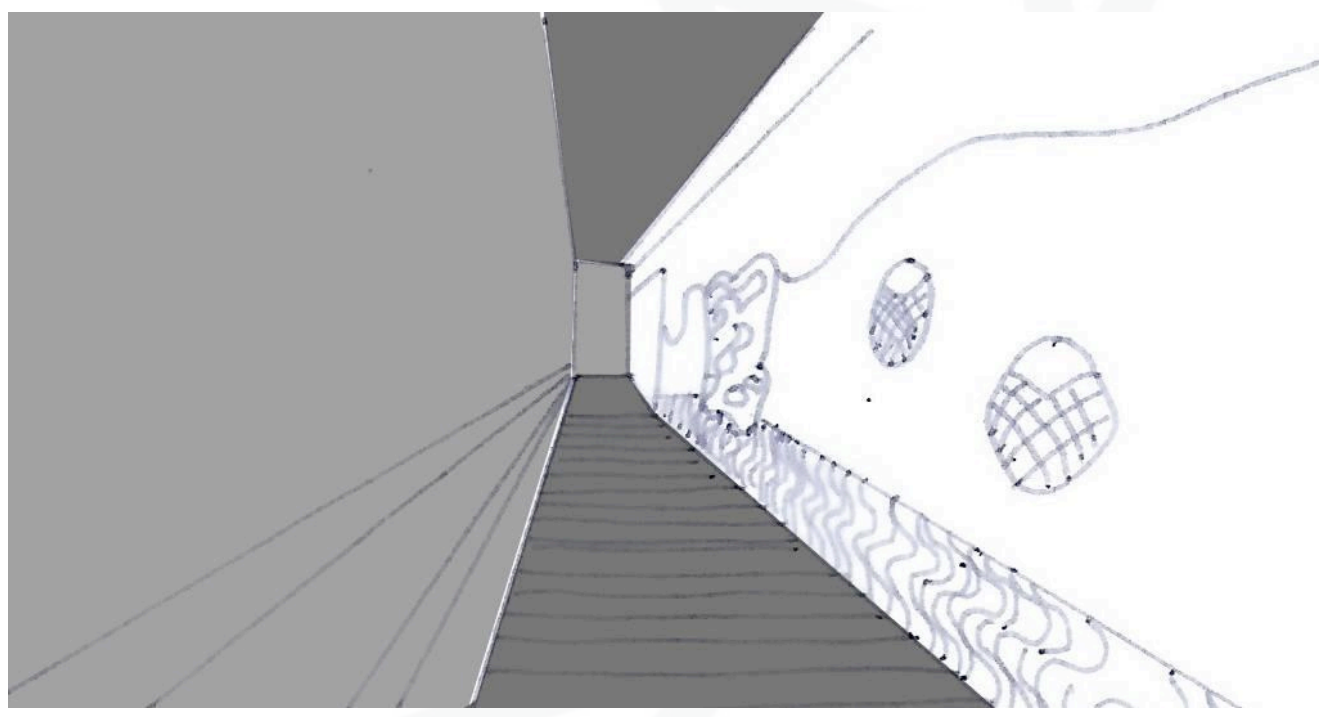

Figura 01- Desenho do corredor do MAM - baseado em vista de tour virtual projeto parede. Desenho da autora.

\section{FIDELIDADE}

A exposição atual em cartaz no museu e com visita virtual, Desafios da modernidade - Família Gomide-Graz nas décadas de 1920 e 1930, com a curadoria de Maria Alice Milliet, traz um aspecto curioso. A mostra é organizada por ambientes bem definidos, ordenados como salas, composta por móveis, telas e tapeçarias, em sequência no espaço do museu, definidas pela saturação das paredes de cada ambiente. Os cômodos formados pelo piso elevado e paredes intercalam-se por intervalos abertos, permitindo acesso para a empena de vidro com vista ao parque, visuais ao exterior nos intervalos das paredes posicionadas na expografia. Uma vez que o próprio espaço museal simula um ambiente, neste caso, o tour virtual parece ter uma finalidade que extrapola o registro. De acordo com Benjamin, "As traduções, por outro lado, provam serem intraduzíveis não por causa do seu peso mas sim por razão da ligeireza (arbitrariedade) com que nelas é fixado o significado." (BENJAMIN (1923), 2008, p. 41). A aproximação expográfica em recriar um ambiente interno, reconstituindo interiores das casas burgueses desenhadas pelos artistas, com a 
concepção do desenho total, em peças do mobiliário, tapeçarias, estampas e telas, já se configuram como uma tradução de um espaço anterior, assim sendo, a reprodução virtual e o tour digital, permitem de algum modo percorrer e se aproximar dos ambientes, de modo muito parecido com que o visitante o faz no local. Em certa medida, perdem-se texturas, contrastes e cheiros, tonalidades e outros aspectos característicos da riqueza e pluralidade de materiais que se reconstituem nestes ambientes. Porém a linguagem utilizada nos passeios virtuais, o distanciamento fixado que se estabelece de algum modo está também representado na forma de registro virtual, conferindo alguma fidelidade entre ambos.

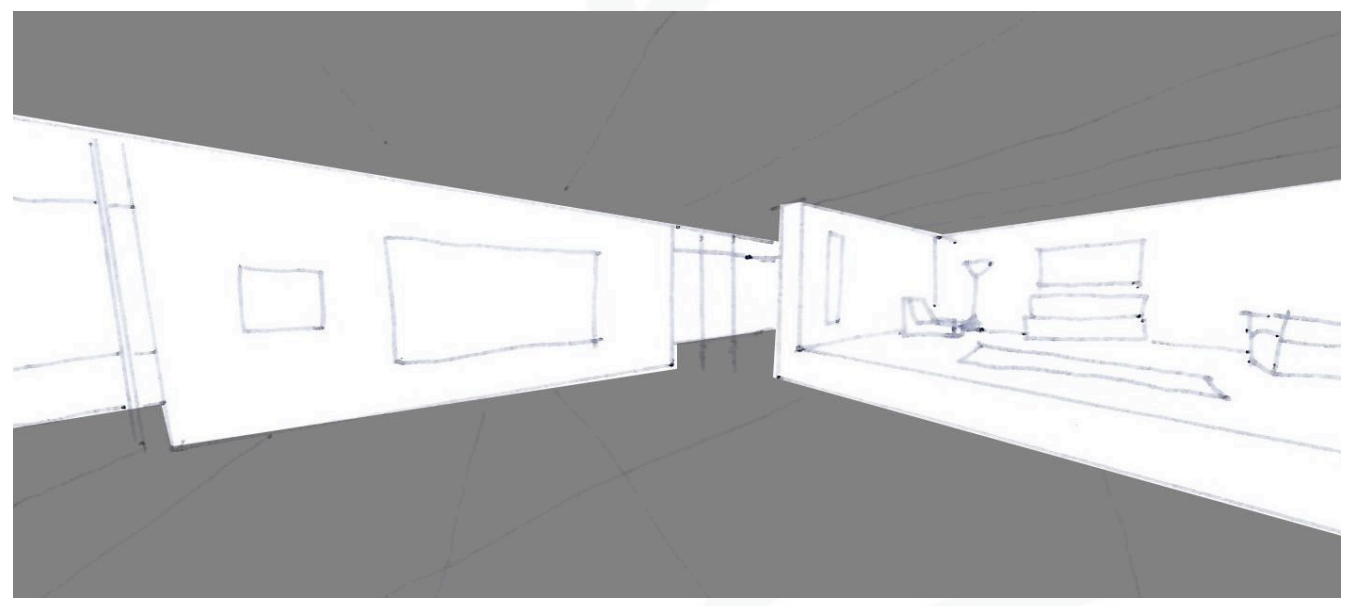

Figura 2 - Desenho da exposição baseado na imagem da maquete virtual Família Gomide-Graz nas décadas de 1920 e 1930. Desenho da autora.

Retomando as teses de Benjamin sobre a tradução, o problema colocado está entre a tradução aspirar ser uma reprodução parecida ou semelhante ao original ou em afinidades determinadas com o original: "A tradução nunca consegue na verdade revelar, nunca consegue estabelecer esta relação oculta; pode todavia apresentá-la na medida em que de modo incoativo intensifica ou fecunda a sua essência embrionária" (2008, p.29). A "essência embrionária" estaria residente no que Benjamin menciona como a língua pura. Não cabe neste texto debater o conceito de "língua pura", mas sim compreender sua raiz romântica em associar ao transcendente, aos mistérios e ao sublime. Neste sentido, seu texto procura precisamente distinguir em maior acuidade o que existe de diferente entre o original e a tradução, do que encontrar seus pontos em comum. (BENJAMIN, 1923, p.45). 
A Pinacoteca do Estado de São Paulo apresenta em sua página na web acesso a [portal] duas visitas virtuais, uma às obras do acervo na mostra denominada Arte no Brasil: uma história na Pinacoteca de São Paulo, que ocupou o segundo andar da instituição entre 2016 e 2020. E a outra mostra em cartaz sobre os irmãos artistas grafiteiros do Cambuci na cidade de São Paulo, Os Gêmeos: segredos, que ocupa até o início de agosto de 2021 as instalações da Pinacoteca. Ambos os passeios virtuais são gratuitos e têm proximidade quanto aos modos de apresentação. São registros de uma mostra física, aberta ao público (com acesso controlado após reabertura na pandemia), ou seja, foram montagens "tradicionais", utilizando os espaços, paredes, suportes e as salas da instituição, ambos são maquetes digitais do edifício que permitem o visitante passear por entre as salas, como nos programas de modelagem 3D. Neste caso, os passeios foram executados por empresas diferentes. O tour virtual da exposição do acervo foi executado pela empresa Iteleport, que também hospeda a em sua página e oferece outros serviços de visitas virtuais principalmente para o mercado imobiliário como incorporadores, imobiliárias, espaços comerciais e cultura, termos extraídos do website da empresa. Neste sentido, parece que o ramo que se abre no mercado para este serviço centraliza esforços na venda de seus produtos, distantes das prerrogativas de um espaço institucional museal público que visa preservar, salvaguardar, difundir, investigar e comunicar patrimônio material e imaterial. Neste sentido, o registro soma-se ao conjunto das ações museológicas que muitas vezes são desconhecidas e pouco difundidas para o público.

No caso da mostra sobre os Gêmeos, a exposição teve obras construídas e desenhadas para cada espaço, o diretor da Pinacoteca Jochen $\mathrm{Volz}^{1}$, contou sobre a elaboração da mostra, desde a concepção, o contato e o envolvimento dos artistas. Os Gêmeos possuem uma memória afetiva desde a infância com a Pinacoteca, e o adiamento da abertura da mostra possibilitou maior tempo de montagem. Entre as pausas e as retomadas, houve um o processo de criação e transformação dos artistas nos espaços

\footnotetext{
${ }^{1} \mathrm{O}$ vídeo com o depoimento do Diretor, está na página de acesso ao tour virtual, como um documento complementar à mostra, e conta com detalhes o processo de produção, dificuldades e a relação direta entre os curadores e os artistas na criação e elaboração da exposição. Disponível em:

http://pinacoteca.org.br/tourvirtualosgemeos/
} 
do museu neste período em que a instituição ficou fechada ao público. A visita virtual é um complemento da mostra física, não substitui a experiência e vivência em estar e percorrer os espaços do museu e o contato direto com as obras, assim definiu o próprio diretor sobre os dispositivos tecnológicos e a visita virtual. No caso do tour virtual desta mostra, é nítida uma preocupação maior com a alta resolução na qualidade das imagens apresentadas, além de incluir alguns vídeos em salas específicas, e a inserção do áudio dos ambientes, que foram pensados e executados em parceria com os artistas. Neste caso foi importante registrar já que mostrar a cultura do hip hop é parte das narrativas que constituem a exposição, além da trajetória dos irmãos, o universo imaginário e o cunho crítico social de alguns trabalhos e intervenções. Assim, parece que a pausa obrigatória que a pandemia forçou a instituição trouxe neste caso um ganho de tempo, que contribuiu para incorporar novos trabalhos, revisitar e reelaborar alguns espaços. No caso da visita virtual, aparentemente permitiu maior cuidado e atenção para a qualidade das imagens e sua resolução, no efeito e saturação das cores e dos efeitos sonoros incorporados aos espaços expositivos. Novamente a visita virtual se configura como um apoio e registro da visita física, sem enfrentar qualquer desafio de linguagem ou diálogo com as especificidades do meio digital, centrado na fidelidade e reprodução do seu original.

\section{AFINIDADES}

Outro exemplo em cartaz com a prerrogativa de uma exposição imersiva, digital e interativa, com visita virtual gratuita é promovida pelo Museu da Imagem e do Som (MIS) de São Paulo. O MIS Experience instalado em um galpão no bairro industrial da Água Branca, área de intensa transformação e interesse imobiliário crescente na cidade de São Paulo, tem como proposta abrigar grandes mostras com uso de tecnologias e, como aludem, "experiências multissensoriais". O espaço foi inaugurado em outubro de 2019 com abertura da mostra: Leonardo Da Vinci, 500 anos de um Gênio. Além da visita física, que esteve aberta ao público antes da pandemia e depois teve reabertura e acesso controlado, a versão digital da mostra 
está liberada para acesso do público via internet ${ }^{2}$. Das visitas virtuais citadas, esta parece mesclar o passeio entre a maquete virtual, as fotos em 360 graus e informações textuais sobre a vida e feitos do gênio e seu legado histórico comemorado em 500 anos. Da narrativa individual e enaltecedora, sem discordar da importância histórica da personagem, reitera-se o chavão - o indivíduo gênio sem abrir brechas para o debate de seu contexto, problemas e tensões historiográficas, alia-se ao linear, ascendente e triunfal apelo comercial e franqueado do sistema econômico cultural internacional. Vale aqui uma análise dos aspectos formais da linguagem, em que se mistura no passeio virtual a maquete eletrônica, as fotos em $360^{\circ}$ e o modo de leitura em websites e páginas na internet, com a janela que se amplia com textos em rolagem contínua, imagens com botão de aproximar, o zoom.

Das seções organizadas em seis partes, a primeira chamada códices têm a monotonia textual de longas frases e alguns desenhos interessantes, relatando a história dos cadernos de anotações e os movimentos destes escritos ao longo dos séculos, em coleções e bibliotecas europeias. Daqui extrai-se um pouco sobre a história e movimentos dos objetos e textos consagrados, seu valor e as diferentes representações desenhadas em seu percurso histórico. A sala seguinte, acessada pelo caminho do mouse ou pelo simples clique na barra superior, que anuncia os seis ambientes da mostra. Alguns vídeos explicativos têm o narrador ou narradora contando de modo sucinto um pouco da história de cada trecho selecionado. Assim sucedem-se o ambiente civil, este mais atrativo do ponto de vista expográfico, com os objetos tridimensionais construídos, explicações, imagens, fotos e muitos textos. Um novo recurso é utilizado, a chamada realidade aumentada, em que uma maquete tridimensional virtual se abre na tela e pode-se ampliar e diminuir, além de visualizar as peças isoladas e seu encaixe. A galeria mista se assemelha à anterior, inserindo algumas telas em meio aos objetos decifrados e reconstruídos. Neste caso há um diálogo, ainda que discreto, entre o caminhar robotizado das maquetes eletrônicas e o acesso visual aos desenhos e textos, sem grandes surpresas e descobertas.

\footnotetext{
${ }^{2}$ Inicialmente havia um procedimento de ingresso, cadastro e a liberação de um código para visita virtual, atualmente a exposição é acessada diretamente pelo endereço disponibilizado no site do MIS.
} 
Talvez o momento mais interessante seja a galeria sensorial, embora novamente a presença física neste espaço potencializa os efeitos da luz e do som, e no modo virtual se aproxima da possibilidade imersiva, pelo ritmo da música e sucessão de imagens, em sintonia. São imagens de quadros, desenhos e fotografias projetadas em grande escala sob grandes telas, com aproximadamente seis metros de altura. Tal efeito monumental desaparece e não se aplica pela tela do computador: é preciso imaginar-se no ambiente imersivo, somente a cadência entre imagens e músicas que tocam de algum modo o espectador estático, sentado em frente ao computador, ainda em diferente posição a caminhar de quem está no galpão, circulando entre as telas e observando duplamente a movimentação das imagens projetadas em múltiplas telas e no chão.

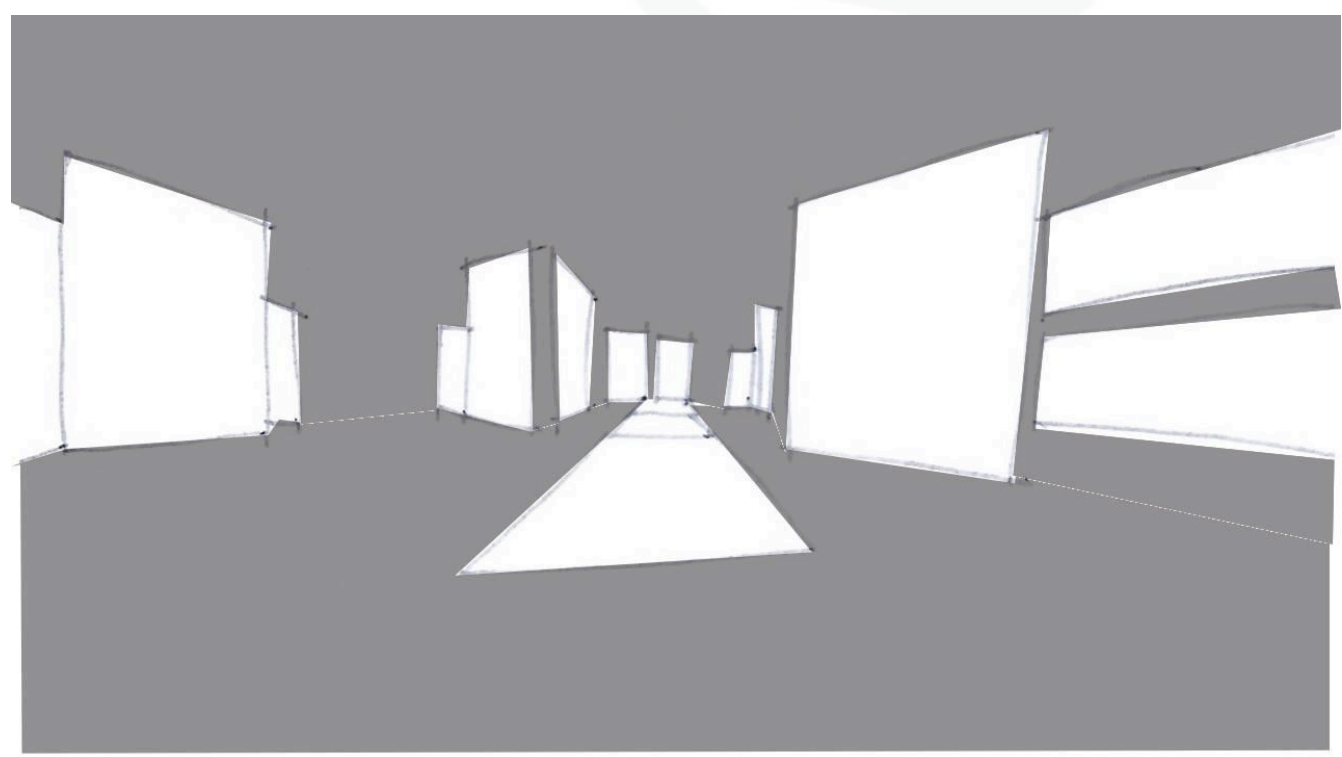

Figura 3 - Desenho da autora, baseado na imagem da sala sensorial do tour virtual da exposição Leonardo Da Vinci, 500 anos de um Gênio. Desenho da autora.

Das salas seguintes o militar aproxima-se dos anteriores, com objetos, textos e desenhos, e por fim a Monalisa, neste ambiente a ênfase é a tecnologia aliada a análise da tela, suas cores, as sucessivas camadas de tinta e verniz, elementos de cada parte da tela são estudados e demonstrados na tentativa de evidenciar ao público as razões de tamanha importância dada à madonna de Leonardo da Vinci. Arriscaria aqui, aproximar a ideia de afinidade que Benjamin utiliza em seu texto, ao 
“encontrar na língua em que se está traduzindo aquela intenção por onde o eco do original pode ser ressuscitado" (2008, p.35), o ambiente sensorial da mostra seja pela natureza das telas planas e da sintonia com a música, tenha alguma afinidade com o original, seja pelo sequenciamento das imagens, evidenciando cores e texturas, variadas escalas somadas ao som ambiente, que alinha o movimento visual ao ritmo sonoro, encadear pensamentos livres e interpretações variadas, indefinições e aberturas pouco usuais tanto nos espaços físicos como nos ambientes virtuais.

A condição da pluralidade das línguas, que segundo Giorgio Agamben no ensaio $A$ tarefa do tradutor de 1921, é que torna possível a pura língua, na totalidade das suas intenções, no fim messiânico de sua história. Assim como a história, o movimento linguístico como um todo tende a um estágio último, definitivo e decisivo de toda estrutura linguística. Cabe ao filósofo e ao tradutor, a descrição e o pressentimento dessa língua única e verdadeira, ao final descrita como palavra sem expressão. Segundo Benjamin, todas as línguas históricas querem dizer a pura língua. Conclui Agamben "[...] poderemos assim dizer que todas as línguas querem dizer a palavra que não quer dizer nada" (AGAMBEN, 2013, p.40). A relação entre as múltiplas línguas históricas e a coisa única que elas visam é dialética.

\title{
CONSIDERAÇÕES FINAIS
}

\begin{abstract}
(...) Ah, mas para se chegar à mudez, que grande esforço da voz. Minha voz é o modo como vou buscar a realidade; a realidade, antes de minha linguagem, existe como um pensamento que não se pensa, mas por fatalidade fui e sou impelida a precisar saber o que o pensamento pensa. A realidade antecede a voz que a procura, mas como a terra antecede a árvore, mas como o mundo antecede o homem, mas como o mar antecede a visão do mar, a vida antecede o amor, a matéria do corpo antecede o corpo, e por sua vez a linguagem um dia terá antecedido a posse do silêncio. (LISPECTOR, 2014, p.119)
\end{abstract}

Museus e instituições culturais no país estão ainda em busca de traduções para o encontro com seus respectivos acervos e programação na pandemia. Lives, oficinas, palestras e aulas parecem ter no meio digital uma importante maneira para se 
propagar de modo eficaz, rápido e em massa. E quanto às exposições? O tour virtual é equivalente a uma visita? De que modo é possível a fruição, um percurso que possa de alguma forma, mesmo que de modo pontual tocar um aspecto do que se refere o espaço original? E quanto ao acesso e sua necessidade de aparelhos atualizados e conexões velozes para realizar passeio, inclui ou exclui parcela representativa da população brasileira?

Do período que ainda vivenciamos, em meio à crise sanitária sistêmica mundial, a obrigatoriedade do isolamento social, necessária mudança de hábitos e invenção de outras rotinas, medidas de distanciamento corporal e a imersão na imensidão da realidade digital, são interferências agudas em sensibilidades que propõem alguns questionamentos quanto aos vícios, fragilidades, medos e alteridades. A percepção humana varia de acordo com a rasa profundeza dos bits e das imagens assistidas em velocidades cada vez maiores, e por dispositivos cada vez menores.

O que seria essencial de uma exposição virtual e como se operam as traduções dos espaços em meio digital? Talvez seja ainda incipiente qualquer conclusão, há um vasto campo a investigar sobre a imersão nas linguagem e domínio dos códigos para o que Benjamin relata como o poder do tradutor, "restaurar a língua pura que é formada no movimento da língua" (BENJAMIN, 2017, p.40).

\section{BIBLIOGRAFIA}

AGAMBEN, G. A ideia da linguagem. In: A potência do pensamento Ensaios e Conferências. Belo Horizonte: Autêntica, 2017.

BENJAMIN, W. (1916). Sobre a linguagem em geral e sobre a linguagem humana. In: Escritos sobre mito e Linguagem. São Paulo: Ed. 34; 2013.

(1923). A tarefa do tradutor. Tradução de Fernando Camacho. Revista Humboldt, Munique, F. Bruckman, n.40, p.38-45, 1979.

(1923). A obra de arte na era de sua reprodutibilidade técnica, in Magia e técnica, arte e política. São Paulo: Brasiliense, 1987.

Origem do Drama Barroco Alemão (1928). Trad. br. Sérgio Paulo Rouanet. São Paulo: Ed. Brasiliense, 1984.

Língua e História. In: A potência do pensamento Ensaios e Conferências. Belo Horizonte: Ed. Autêntica, 2017. 
BRANCO, Lúcia Castello (org.). A tarefa do tradutor de Walter Benjamin: quatro traduções para o português. Belo Horizonte: Fale/UFMG, 2008. Disponível em: http://escritoriodolivro.com.br/bibliografia/Benjamin.pdf. Acesso em: 23 jul.2021.

DIDI-HUBERMAN, G. Diante do tempo: história da arte e anacronismo das imagens. Tradução Vera Casa Nova, Márcia Arbex. Belo Horizonte: Editora UFMG, 2015.

ICOM BRASIL, Dados para navegar em meio às incertezas: resultados da pesquisa com profissionais e públicos de museus. Disponível em:http://www.icom.org.br/wpcontent/uploads/2020/11/20201120_Tomara_ICOM_SumarioExecutivo_FINAL .pdf. Acesso em:15.ago.2021.

LISPECTOR, Clarice. A paixão segundo G.H. Rio de Janeiro: Rocco, 2009.

\section{Websites e endereços das mostras virtuais}

DA VINCI, Leonardo - 500 anos de um gênio. Disponível em: https://exposicaodavinci500anos.com.br/\#/experience. Acesso em: 01 ago. 2021.

TOUR VIRTUAL - Exposição OSGEMEOS: Segredos. Disponível em: http://pinacoteca.org.br/tourvirtualosgemeos/. Acesso em: 01 ago. 2021.

PINACOTECA DE SÃO PAULO - acervo permanente tour virtual. Disponível em: https://www.portal.iteleport.com.br/tour3d/pinacoteca-de-sp-acervopermanente/. Acesso em: 30 jul. 2021.

TOUR VIRTUAL - Exposições do MAM. Disponível em: https://mam.org.br/2020/03/18/tour-virtual-pelas-exposicoes-do-mam-saopaulo-museu/. Acesso em: 30 jul. 2021. 